$10-25-2006$

\title{
Evolution of Surface Morphology of Thermo-Mechanically Cycled NiCoCrAIY Bond Coats
}

J. Shi

University of Delaware

Anette M. Karlsson

Cleveland State University, a.karlsson@csuohio.edu

B. Baufeld

German Aerospace Center

M. Bartsch

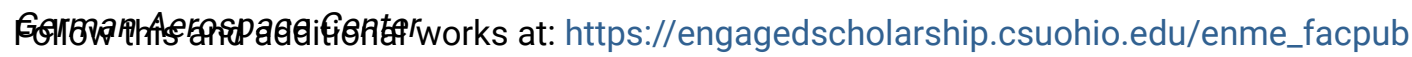

Part of the Mechanical Engineering Commons

How does access to this work benefit you? Let us know!

\section{Publisher's Statement}

NOTICE: this is the author's version of a work that was accepted for publication in Materials Science \& Engineering A. Changes resulting from the publishing process, such as peer review, editing, corrections, structural formatting, and other quality control mechanisms may not be reflected in this document. Changes may have been made to this work since it was submitted for publication. A definitive version was subsequently published in Materials Science \& Engineering A, 434, 1-2, (10-25-2006); 10.1016/j.msea.2006.07.048

\section{Original Citation}

Shi, J., Karlsson, A. M., Baufeld, B., 2006, "Evolution of Surface Morphology of Thermo-Mechanically Cycled NiCoCrAlY Bond Coats," Materials Science \& Engineering A, 434(1-2) pp. 39-52.

This Article is brought to you for free and open access by the Mechanical Engineering Department at EngagedScholarship@CSU. It has been accepted for inclusion in Mechanical Engineering Faculty Publications by an authorized administrator of EngagedScholarship@CSU. For more information, please contact library.es@csuohio.edu. 


\title{
Evolution of surface morphology of thermo-mechanically cycled $\mathrm{NiCoCrAlY}$ bond coats
}

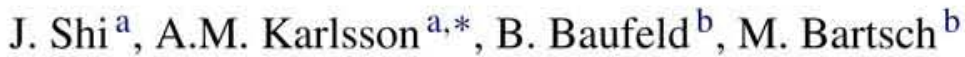 \\ a University of Delaware, Newark, DE 19716-3140, USA \\ ${ }^{\mathrm{b}}$ The German Aerospace Center (DLR), D-51147 Cologne, Germany
}

\section{Introduction}

Thermal barrier coatings (TBCs) are commonly used to protect components exposed to extreme temperatures in gas turbines. The coatings typically consist of three layers: (1) a metal bond coat deposited on the superalloy substrate; (2) a thermally grown oxide (TGO) - primarily $\alpha$-alumina - that forms during high temperature exposure; and (3) a ceramic top coat. Internal cooling of the substrate allows the coating system to sustain a thermal gradient of about $150^{\circ} \mathrm{C}$ during high temperature operations, thus reducing the temperature the superalloy is subjected to. This potentially allows the gas turbine to operate at higher temperatures, which increases the fuel efficiency and/or extend the lifetime of the gas turbine. Unfortunately, premature failures, such as spallation of the TBC from the substrate, limit the use of TBCs as a prime-reliant material. Due to the complex nature of a TBC - including evolving material properties during use the failure process is not completely understood. Depending on the operating profile (e.g., energy generation versus propulsion) and the material system used, failure modes can be suppressed

\footnotetext{
* Corresponding author. Tel.: +1 302831 6437; fax: +1 3028313619.

E-mail address: karlsson@udel.edu (A.M. Karlsson).
}

or enhance, completely changing the evolution of the failure modes [1].

In this paper, failure evolutions relating to morphological surface instabilities of the bond coat will be discussed [2-6]. In this case, the TGO deforms on a cyclic basis, causing large undulation of the bond coat surface. It is characterized by that the undulation growth only occurs if the system is cycled: if the same material system is subjected to isothermal conditions, undulation growth will not occur. The key parameters causing the surface instabilities are (i) thermal mismatch, (ii) growth strain in the TGO, (iii) non-elastic strain in bond coat and TGO, and (iv) cyclic loading. Moreover, the instabilities only occur when the ceramic top coat has detached locally from the TGO, either by the top coat completely spalling from the surface or from sufficiently large cracks developing between the TGO and the top coat. If any of these factors are removed (e.g., isothermal conditions instead of thermal cycling), the morphological instabilities do not occur. Morphological instabilities are associated with a highly non-linear cyclic response, and for clarification, some details of this process are summarized in Appendix A.

Recently the development of morphological instabilities in Pt-aluminides bond coats have received significant attention, e.g. [4-7]. In addition, MCrAlY-type bond coats have been shown prone to develop these features on aerospace turbine blades in 
service conditions, and in thermal cyclic with maximum temperatures at $1100^{\circ} \mathrm{C}[8,9]$.

We will investigate the development of morphological instabilities observed in a NiCoCrAlY coated system subjected to thermo-mechanical cycling. The NiCoCrAlY was applied by electron beam physical vapor deposition (EP-PVD), which provided a smooth surface with roughness below $1 \mu \mathrm{m}$. The relevant observations pertain to parts of the specimens where the ceramic topcoat (intentionally) had spalled $[10,11]$. The morphological instabilities developed during thermal cycling with a thermal gradient over the cylinder wall, whereas the surface remains smooth for cyclic conditions without a thermal gradi- ent. Furthermore, if an axial tensile force (synchronized with the thermal cycling) is applied, the morphological instabilities become aligned with the axial direction. The purpose of this paper is to explore and explain how the morphological instabilities are related to the load conditions.

\section{Experiments}

\subsection{Test procedure}

The thermo-mechanical test specimens consist of a hollow circular cylinder with an inner diameter of $4 \mathrm{~mm}$ and an outer
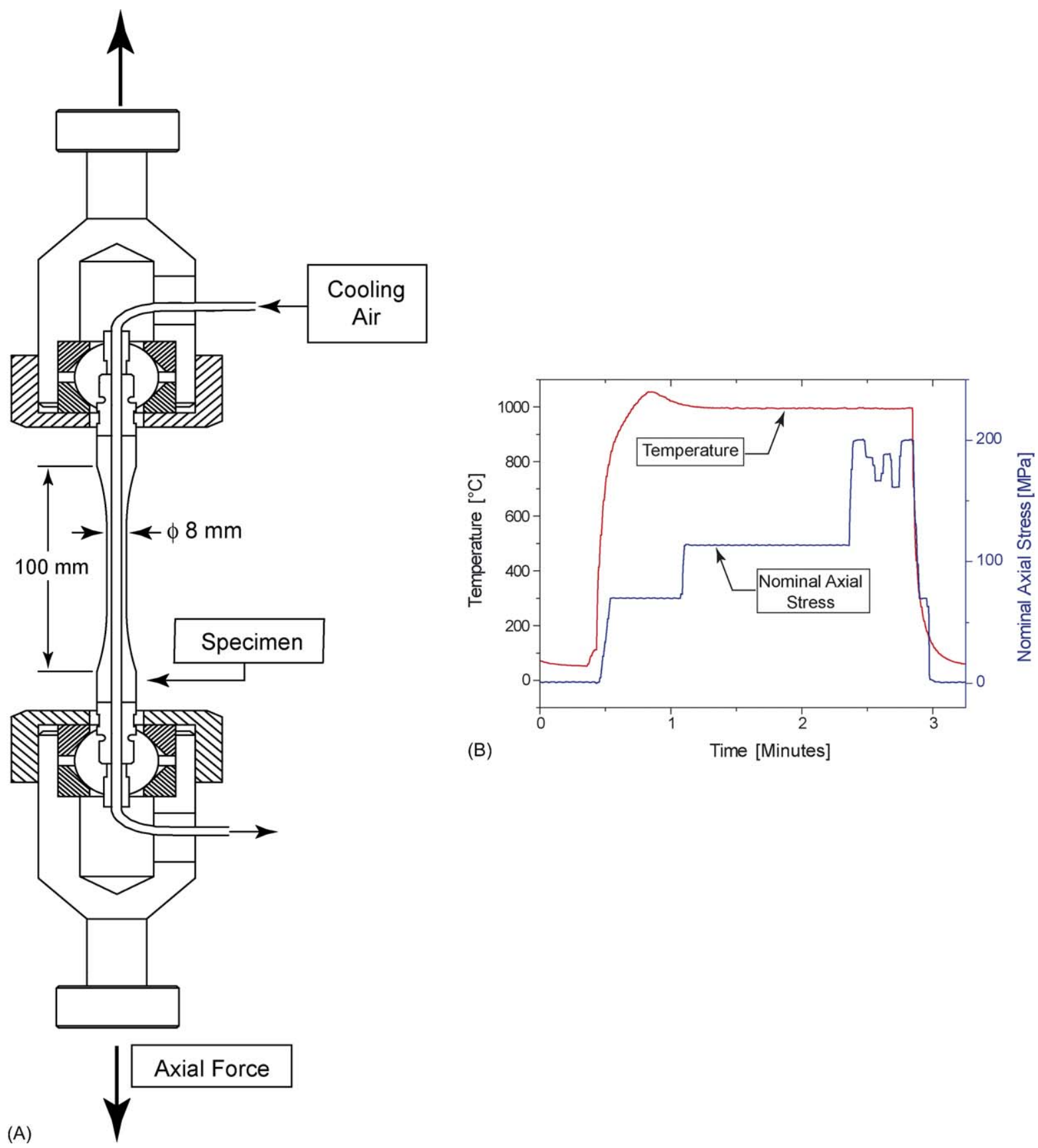

Fig. 1. (A) Schematic drawing of experimental setup; (B) estimated temperature at the outer wall and axial tensile force as a function of time for one typical load cycle. 
diameter of $8 \mathrm{~mm}$, made of nickel-based directionally solidified superalloy, IN 100 DS coated with approximately $110 \mu \mathrm{m}$ thick NiCoCrAlY (in wt $\%$ : 20Co, $21 \mathrm{Cr}, 12 \mathrm{Al}, 0.15 \mathrm{Y}+\mathrm{Ni}$ ) bond coat and approximately $220 \mu \mathrm{m}$ thick top coat of YSZ (7-8 wt \% Yttria) [12]. Both coatings were applied by EB-PVD.

The specimens were placed in a specially developed test facility, which was developed by the German Aerospace Center in Cologne, Germany, in order to generate conditions as close to service conditions as possible for the TBC-system. Fig. 1A shows a sketch of the specimen fixture assembly.

The specimens were subjected to simultaneous thermal and mechanical cycling. The mechanical load (an axial tensile force) was applied by a servo-hydraulic testing machine and the thermal load with a radiation furnace powered by four cylindrical quartz lamps, each with a maximal power of $2 \mathrm{~kW}$. The radiation of the quartz lamps was focused onto the specimen with elliptical mirrors in a way that the lamps were in one focus line of each mirror and the specimen in the other focus line. The length of the heating coil of the lamps was $60 \mathrm{~mm}$ and optical efficiency of the configuration about $35-40 \%$. Thus, with a total maximal power of the quartz lamps of $8 \mathrm{~kW}$, a maximum heat flux of $1 \mathrm{MW} / \mathrm{m}^{2}$ was imposed to the specimen. The power output of the lamps was controlled by the outer surface temperature of the specimen, which was measured with a thin wire thermocouple $(\varnothing 0.3 \mathrm{~mm}$, Type $S)$ enlacing the specimen. The maximum temperature set-point value was $1000^{\circ} \mathrm{C}$ and the minimum set-point value about $100^{\circ} \mathrm{C}$. This temperature range corresponds to typical field conditions for thermal barrier systems $[1,13-15]$. During the heating sequence of the thermal cycle (compare Fig. 1B) the maximum power was supplied. Steadystate conditions, indicated by a reduced constant electrical power of about $4.5 \mathrm{~kW}$ consumed by the quartz lamps, were reached after about $2 \mathrm{~min}$. High cooling rates were achieved with an active air cooling from vents in a shutter, which was introduced into the furnace by a pneumatic device and enclosed the specimen during the cooling cycle. The temperature of the external cooling air was about $20^{\circ} \mathrm{C}$. By removing the shutter under full radiation power very high heating rates were attained. During the fatigue testing the specimen was permanently internally cooled by a constant air flow. The inlet temperature of the internal cooling air was about $270^{\circ} \mathrm{C}$. Internal cooling and external heating and cooling, respectively, generated thermal gradients over the cross-section of the specimen.

With a thermal gradient present, we refer to this test as thermal gradient mechanical fatigue (TGMF), in contrast to thermomechanical fatigue (TMF) absent a thermal gradient. The temperature difference between the outer and the inner surface was measured at a calibration specimen with sheet thermocouples at different radial locations. Under quasi-stationary conditions, during the high temperature sequence of the test cycle, a temperature difference between the inner and outer surface of about $170{ }^{\circ} \mathrm{C}$ was measured. The real temperature difference was a bit higher since the measurements were performed under geometric constraints. The transient temperature differences during heating and cooling could not be measured due to the thermal inertia of the sheet thermocouples. The tests were force controlled with respect to an axial tensile force, representing the
Table 1

Testing scheme

\begin{tabular}{lll}
\hline Type of test cycle & Thermal gradient & Axial tensile force \\
\hline $\begin{array}{l}\text { Thermal fatigue (TF) } \\
\begin{array}{l}\text { Thermal gradient fatigue } \\
\text { (TGF) }\end{array}\end{array}$ & No & No \\
$\begin{array}{l}\text { Thermal gradient mechanical } \\
\text { fatigue (TGMF) }\end{array}$ & Yes & No \\
\end{tabular}

centrifugal forces in a rotating gas turbine blade. Fig. 1B shows the outer surface temperature and the nominal axial tensile force related to the substrate cross-section during the course of one TGMF test cycle. The duration of one TGMF cycle was about $3 \mathrm{~min}$ and aimed to simulate the entire low cycle fatigue load of a turbine blade during one flight. A detailed description of the Thermal Gradient Mechanical Fatigue Testing Facility is given elsewhere [15].

Before the tests, the TBC coated specimens were indented with a Rockwell brale $\mathrm{C}$ indenter generating a local delamination and spallation of the TBC. This was done so to study the evolution of an initial flaw in the TBC. Several sets of tests where conducted, but in the following, we will only focus on three basic tests, as described in Table 1.

\subsection{Experimental results}

We will focus on the results pertaining to the evolution of bond coat surface morphology under the delaminated top coat caused by the indentation prior to the testing. Since the top coat debonded due to the indentation, the bond coat was not subjected to a constraint due to the top coat. (A top coat constrains morphological instabilities [16].) For the case of thermal fatigue (TF) - no thermal gradient - the bond coat surface remains flat (Fig. 2A). However, when a thermal gradient is present (thermal gradient fatigue, TGF), development of surface morphology is observed (Fig. 2B), and if an axial tensile force is applied (thermal mechanical gradient fatigue), the instabilities align with the axis of the specimen (Fig. 2C). In the following sections, we investigate and explain some critical parts of this response.

\section{Analytical preliminaries}

The thermal gradient over the cylinder wall induces a stress gradient. We will here develop a simple mechanics based, elastic model with the purpose of demonstrating the effect a thermal gradient over the cylinder wall has on the mechanical stresses of a multilayered circular cylinder. This will reveal some of the basic responses of the system under investigation. To this end, consider a hollow, circular composite cylinder, subjected to temperature $T_{\text {inner }}$ on the inside and $T_{\text {outer }}$ on the outside of its walls. Assume the cylinder consist of three layers, numbered 1,2 and 3. Let $a_{i}$ be the inner diameter and $b_{i}$ outer diameter of layer $i$, where $i=1,2$ or 3 . We note that $b_{1} \equiv a_{2}$ and $b_{2} \equiv a_{3}$. For the test specimen discussed above, these layers correspond to the substrate, the bond coat and the TGO, respectively. (The top coat is ignored since for the problem of interest it had spalled 


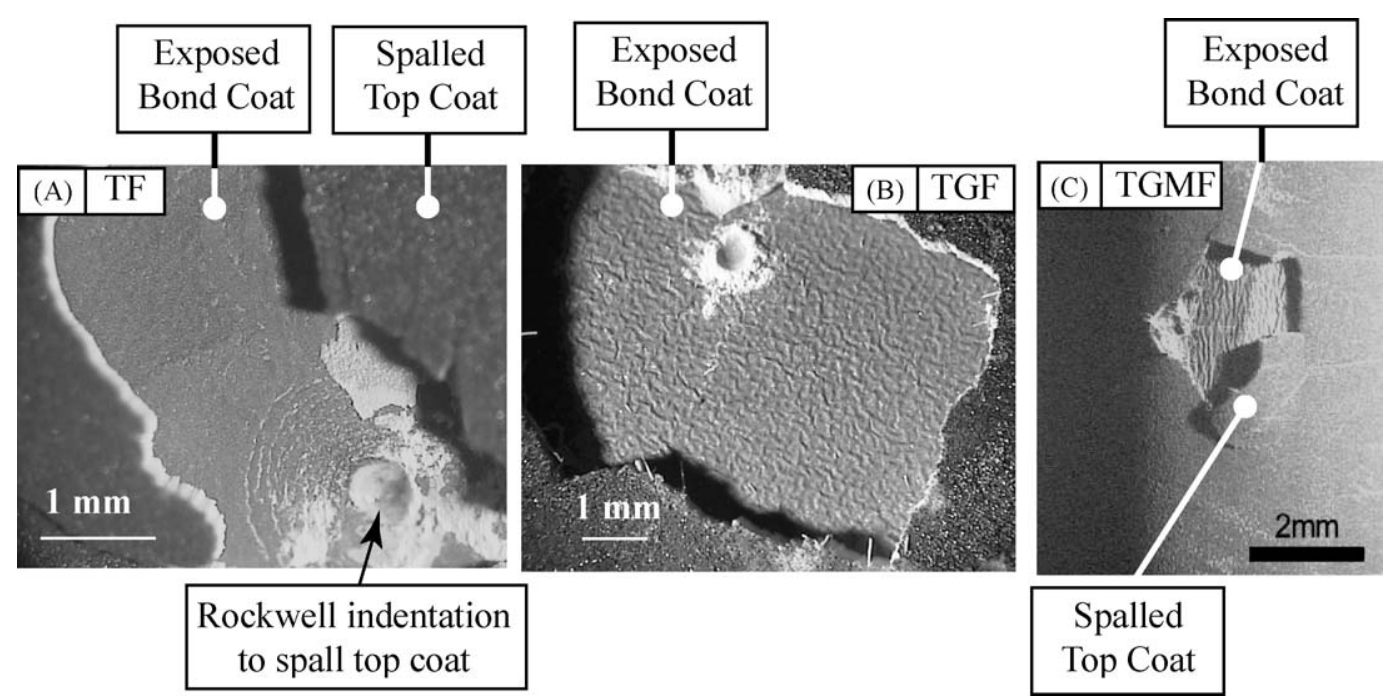

Fig. 2. Surfaces of the bond coat after 500 thermal cycles: (A) thermal fatigue; (B) thermal gradient fatigue; (C) thermal gradient mechanical fatigue.

from the area of interest. As can be seen from what follows, this layer can easily be added to the equations.)

For this analytical study, steady-state conditions will be assumed, corresponding to the conditions dominating the experiment after about $2 \mathrm{~min}$ of the thermal cycle. To this end, Fourier's law for heat transfer may be used. Thus, for given temperatures at the inner and outer wall, the temperatures at the interfaces are given by

$T_{1}\left(b_{1}\right) \equiv T_{2}\left(a_{2}\right)=T_{\text {inner }}+\frac{R_{1}}{R}\left[T_{\text {outer }}-T_{\text {inner }}\right]$

$T_{2}\left(b_{2}\right) \equiv T_{3}\left(a_{3}\right)=T_{\text {inner }}+\frac{R_{1}+R_{2}}{R}\left[T_{\text {outer }}-T_{\text {inner }}\right]$.

In Eqs. (1a) and (1b), $R$ is the "thermal resistance" given by [17]

$R=R_{1}+R_{2}+R_{3}$

$R_{i}=\frac{1}{2 \pi} \frac{1}{k_{i}} \ln \frac{b_{i}}{a_{i}}, \quad i=\{1,2,3\}$,

where $k_{i}$ is the thermal conductivity for layer $i$, and index $i=\{1$, $2,3\}$ refers to layer 1,2 or 3, respectively. An analytical, elastic calculation assuming steady-state, predicts the following stresses, as a function of the radius, $r$, in the radial $\sigma_{r}^{(i)}(r)$ and tangential $\sigma_{\theta}^{(i)}(r)$ direction, respectively, for the circular layer, $i$ [18],

$\sigma_{r}^{(i)}(r)=C_{1 i}+C_{2 i} \frac{1}{r^{2}}-\alpha_{i} E_{i} \frac{1}{r^{2}} \int_{s=a_{i}}^{r} T_{i}(s) s \mathrm{~d} s$,

$i=\{1,2,3\}$,

$$
\begin{aligned}
\sigma_{\theta}^{(i)} & =C_{1 i}-C_{2 i} \frac{1}{r^{2}}-\alpha_{i} E_{i}\left(T_{i}(r)-\frac{1}{r^{2}} \int_{s=a_{i}}^{r} T_{i}(s) s \mathrm{~d} s\right), \\
i & =\{1,2,3\},
\end{aligned}
$$

where $\alpha_{i}$ is the thermal expansion coefficient, $E_{i}$ the elastic modulus and we note that $T_{i}$ is the change in temperature from the reference temperature where the cylinder is in a stress free state. $C_{1 i}$ and $C_{2 i}$ are constants that are solved based on the boundary and continuity conditions. The temperature distribution, $T_{i}$, is given by

$T_{i}(r)=\left[T_{i}\left(a_{i}\right)-T_{i}\left(b_{i}\right)\right] \frac{\ln \left(b_{i} / r\right)}{\ln \left(b_{i} / a_{i}\right)}+T_{i}\left(b_{i}\right)$.

The boundary conditions are given by vanishing pressure on both inner and outer surface:

$\sigma_{r}^{(1)}\left(a_{1}\right)=0$

and

$\sigma_{r}^{(3)}\left(b_{3}\right)=0$.

The continuity conditions are given by the requirement of continuity of the interfacial radial stress (interfacial pressure):

$\sigma_{r}^{(1)}\left(b_{1}\right)=\sigma_{r}^{(2)}\left(a_{2}\right)$

and

$\sigma_{r}^{(2)}\left(b_{2}\right)=\sigma_{r}^{(3)}\left(a_{3}\right)$,

and by the requirement of continuous tangential strain, $\varepsilon_{\theta}^{(i)}$, due to the symmetry of the problem:

$\varepsilon_{\theta}^{(1)}\left(b_{1}\right)=\varepsilon_{\theta}^{(2)}\left(a_{2}\right)$

and

$\varepsilon_{\theta}^{(2)}\left(b_{2}\right)=\varepsilon_{\theta}^{(3)}\left(a_{3}\right)$,

where

$\varepsilon_{\theta}^{(i)}(r)=\frac{1}{E_{i}}\left[\sigma_{\theta}^{(i)}(r)-v_{i} \sigma_{r}^{(i)}(r)\right]+\alpha_{i} T_{i}(r)$.

Conditions (7a) and (7b) are equivalent with a requirement of continuity of the deformation in the radial direction. Thus, the six conditions in Eqs. (5a), (5b), (6a), (6b), (7a), (7b) will solve the six unknown constants in Eqs. (3a) and (3b). 
Table 2

Material properties used for the analytical calculation in Fig. 3 (constant properties are assumed)

\begin{tabular}{|c|c|c|c|c|c|}
\hline & Elastic modulus $E(\mathrm{GPa})$ & Poisson's ratio $v$ & Thermal expansion $\alpha\left(\times 10^{-6}{ }^{\circ} \mathrm{C}^{-1}\right)$ & Thermal conductivity $k\left(\mathrm{~W} / \mathrm{m}^{\circ} \mathrm{C}\right)$ & Thickness (mm) \\
\hline Substrate & 150 & 0.3 & 16 & 30 & 2.0 \\
\hline Bond coat & 100 & 0.3 & 15 & 20 & 0.110 \\
\hline TGO & 310 & 0.2 & 8 & 6 & $1 \times 10^{-3}$ \\
\hline
\end{tabular}

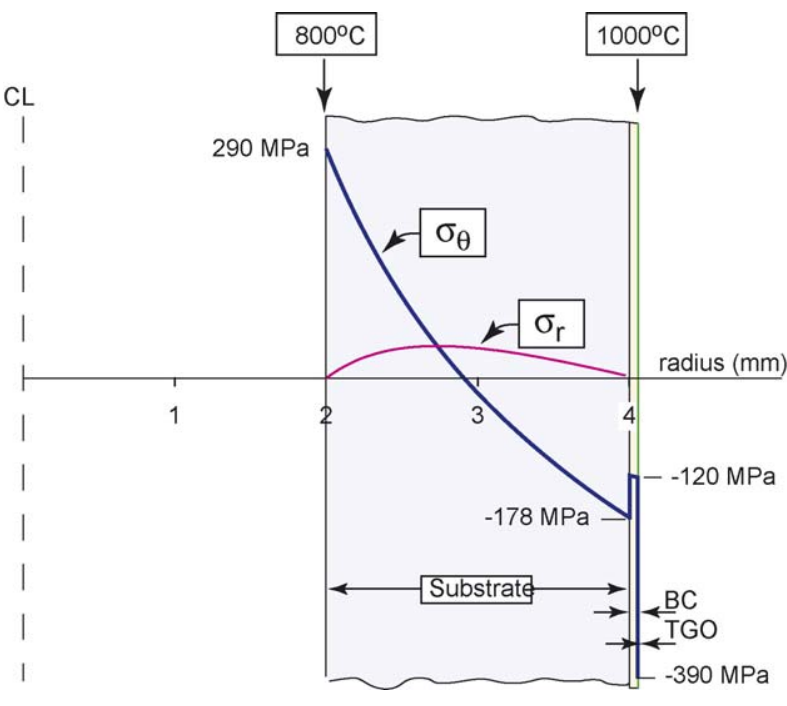

Fig. 3. Example of stress distribution of the radial and the hoop stress ( $\sigma_{r}$ and $\sigma_{\theta}$, respectively) over the wall thickness in a hollow circular, cylinder with a BC and TGO on the outer surface. $T_{\text {inner }}=800^{\circ} \mathrm{C}, T_{\text {outer }}=1000^{\circ} \mathrm{C}$, using material properties in Table 2 (CL, center line).

The explicit analytical solution for this problem (and a four layered system, including the top coat) was derived by Wagus and Karlsson [19] and is omitted here for brevity. However, this problem can easily be solved numerically.

For the current problem of interest, assume that the structure is stress free at $1000^{\circ} \mathrm{C}$ (deposition temperature of the coating). The material properties used for the analytical solution are listed in Table 2. Consider now the case of a thermal gradient over the wall, where the inner temperature is $800^{\circ} \mathrm{C}$ and the outer temperature is $1000^{\circ} \mathrm{C}$. The thermal gradient induces a large gradient in the tangential stress (also referred to as circumferential or hoop stress), resulting in tensile stresses at the inside of the cylinder and compressive on the outside. ${ }^{1}$ The circumferential stress in the bond coat is about $120 \mathrm{MPa}$ (compressive). Thus, with a temperature difference of $200^{\circ} \mathrm{C}$ over the cylinder wall, the bond coat stress is much larger than the high temperature yield strength of typical bond coats (Fig. 3). This suggests that the bond coat is in overall yielding when a thermal gradient of this magnitude is imposed on the system. Moreover, as will be seen below, the inner and outer surfaces do not necessarily reach their $\max / \mathrm{min}$ temperature simultaneously, creating

\footnotetext{
${ }^{1}$ A thermal gradient also introduce an axial stress which is of the same order of magnitude as the hoop stress. For simplicity, this stress is not included in this simple presentation, since the sole purpose of this chapter is to demonstrate that a thermal gradient over a cylinder wall introduces stresses. This stress component will be included later when the numerical simulations are introduced.
}

instantaneous large thermal gradient, leading to large stresses during the heating/cooling sequence.

A previous study on mismatch bond coat stresses and their influence on morphology change [20] reveals that overall compressive stresses in the bond coat enhance morphological

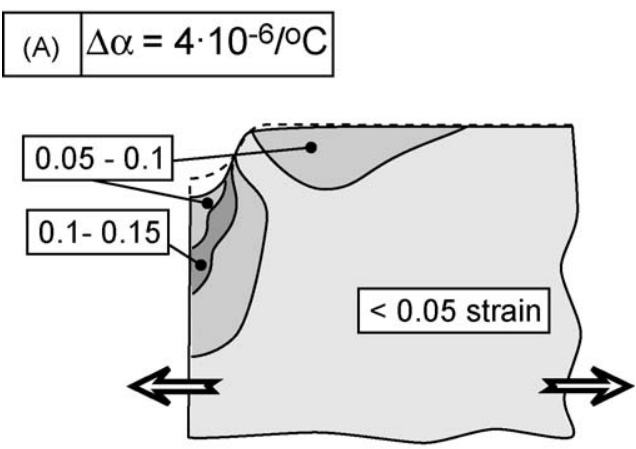

(B) $\Delta \alpha=0$

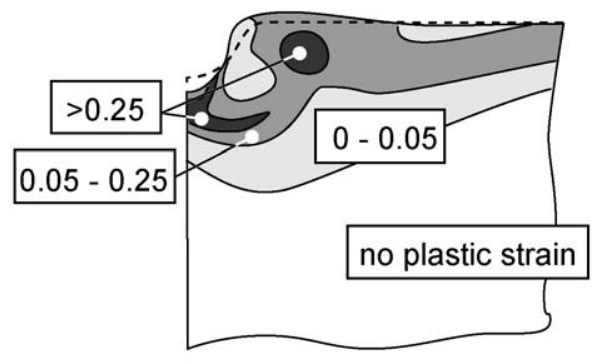

(C) $\Delta \alpha=-4 \cdot 10^{-6} /{ }^{\circ} \mathrm{C}$

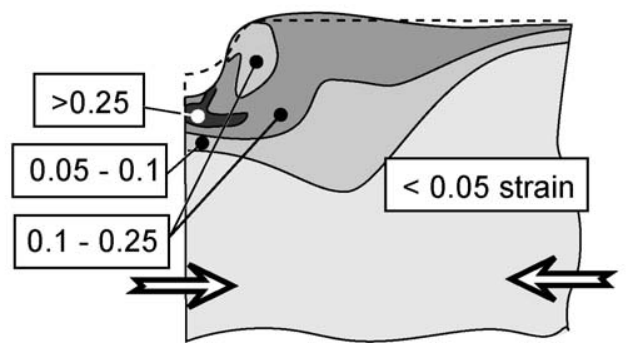

Fig. 4. Example of shape change of the bond coat surface and the accumulated plastic strain after 24 thermal cycles for various levels of thermal mismatch between bond coat and substrate, plotted in deformed state. Dashed line indicates undeformed (initial) geometry. Arrows indicated direction of overall bond coat mismatch stress at lower temperature. Thermal mismatch monitored by $\Delta \alpha=\alpha_{\mathrm{bc}}-\alpha_{\text {sub }}$ where subscript bc and sub refers to bond coat and substrate, respectively, and refers to high temperature properties. (A) $\Delta \alpha=4 \times 10^{-6}{ }^{\circ} \mathrm{C}^{-1}$ (overall tensile bond coat stress); (B) $\Delta \alpha=0{ }^{\circ} \mathrm{C}^{-1}$ (no overall bond coat stress); (C) $\Delta \alpha=-4 \times 10^{-6}{ }^{\circ} \mathrm{C}^{-1}$ (overall compression bond coat stress) [20]. 

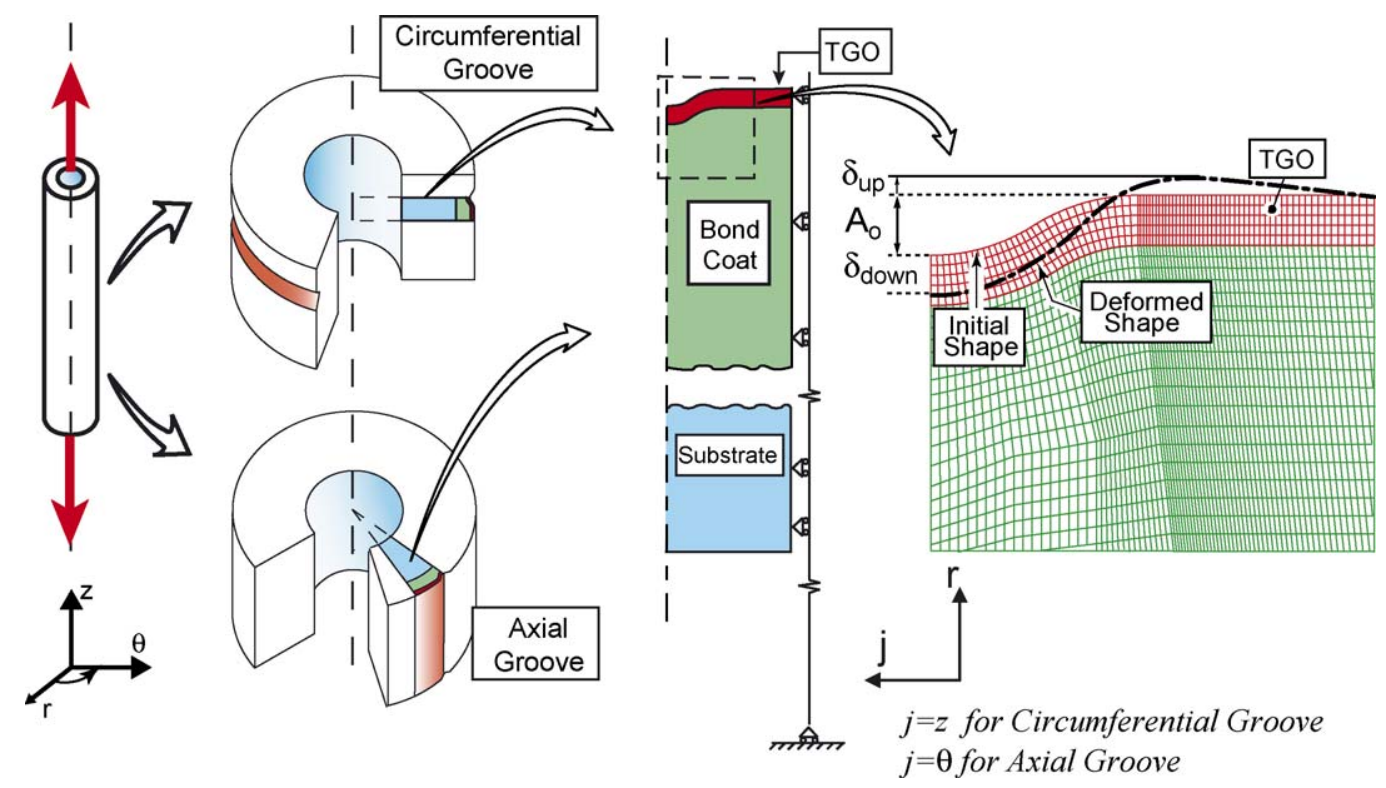

Fig. 5. FE-models for simulating a circumferential groove and an axial groove. Note: $j=z$ for the model with a circumferential groove; $j=\theta$ when simulating an axial groove.

instabilities (Fig. 4). ${ }^{2}$ An overall tensile mismatch stress reduces the compressive stresses around the imperfection, reducing the morphology change driven by the local compressive bond coat stress. The evolution of the morphological instabilities is augmented even further, if the mismatch stresses are large enough to cause overall yielding in the bond coat [20]. The amplitude change is driven by the TGO striving to relax its highly compressive stress (due to growth strain and thermal mismatch) and governed by the local accumulation of plastic strain close to the imperfection. When the bond coat is in overall yielding, the TGO can easily relax its stresses by relaxing into and deforming the relatively soft bond coat.

Thus, the results displayed in Figs. 3 and 4 justify in-depth numerical simulations to see which parameters governs the amplitude change in the problem currently addressed (Fig. 2).

\section{Numerical simulations}

\subsection{Model definition}

Finite element analyses are conducted to simulate the evolution of morphological surface instabilities. The models consist of the substrate, bond coat and the TGO (Fig. 5). The ceramic top coat is omitted since this had spalled in the experimental investigations. A small imperfection with amplitude $A_{0}$ in the bond coat/TGO interface is modeled, serving as a nucleation site for the morphological instabilities. A finite element model,

\footnotetext{
2 In Fig. 4, the sign of the "in-plane" residual stress is indicated with an arrow, showing tensile stress in Fig. 4A and compressive stress in Fig. 4C. The residual stress is the thermal mismatch stress for temperatures below the assumed stress free state $\left(1000^{\circ} \mathrm{C}\right)$. Even though this stress increases linearly with reduced temperature, all yielding occur at temperatures above about $800^{\circ} \mathrm{C}$ in this model. This is so, since the material used in that study has its lowest yield strength for temperatures above $800^{\circ} \mathrm{C}$.
}

based on rate independent elastic-plastic properties, developed for previous studies is adopted [2,3,21,22], utilizing ABAQUS [23].

Here, two two-dimensional (2D) finite element models are used to capture and explain the experimental observations. In these two models, illustrated in Fig. 5, a circumferential groove and an axial groove are simulated, respectively. When simulating the circumferential grooves, axi-symmetric elements are used and the boundary conditions are applied so that the imperfection corresponds to a groove in the circumferential direction. The model simulating an axial groove is modeled with one layer of volume elements in order to facilitate the application of the axial force. However, since there is not a three-dimensional effect present (such as a stress gradient in the third direction), we will still refer to this as a two-dimensional model. The boundary conditions are applied so that the imperfection corresponds to a groove in the axial direction. The latter case corresponds to the alignment of morphology growth as seen in the case of TGMF (Fig. 2C). Both cases are simplification of the real geometry, introduced to keep a tractable scheme and a limited number of parameters, as well as eliminate the need for a full (and time consuming) three-dimensional-model.

Initially, the undulation is $A_{0}=1.0 \mu \mathrm{m}$ and the TGO thickness is $t=1.0 \mu \mathrm{m}$. During thermal cycling, the amplitude change, $\Delta A$, of the imperfection is monitored, where $\Delta A$ is the sum of both the upwards motion at the edge of the imperfection, $\delta_{\mathrm{up}}$, and the downwards motion, in the center of the imperfection, $\delta_{\text {down }}$, i.e., $\Delta A=\delta_{\text {up }}+\delta_{\text {down }}$ (Fig. 5).

For the models to predict the experimental results, $\Delta A$ must be significantly smaller for the case of thermal fatigue (TF, Fig. 2A) compared to thermal gradient fatigue (Fig. 2B), since $\mathrm{TF}$ did not result in any surface roughness. When adding the axial tensile force (TGMF, Fig. 2C), the model simulating the axial grooves must result in a larger amplitude change than the model simulating the circumferential grooves, since the imperfection 
Table 3

Material properties used for the finite element simulations

\begin{tabular}{|c|c|c|c|c|c|}
\hline & $\begin{array}{l}\text { Elastic modulus } \\
E(\mathrm{GPa})\end{array}$ & Poisson's ratio $v$ & $\begin{array}{l}\text { Thermal expansion } \\
\alpha\left(\times 10^{-6}{ }^{\circ} \mathrm{C}^{-1}\right)\end{array}$ & $\begin{array}{l}\text { Thermal conductivity } \\
k\left(\mathrm{~W} / \mathrm{m}^{\circ} \mathrm{C}\right)\end{array}$ & $\begin{array}{l}\text { Yield strength } \\
\sigma_{\mathrm{Y}}(\mathrm{MPa})\end{array}$ \\
\hline Substrate & $\begin{array}{l}212 ; T \leq 100^{\circ} \mathrm{C} \\
148 ; T \geq 1000^{\circ} \mathrm{C}\end{array}$ & 0.3 & $\begin{array}{l}11.5 ; T \leq 100^{\circ} \mathrm{C} \\
16.28 ; T \geq 1000^{\circ} \mathrm{C}\end{array}$ & $\begin{array}{l}15.3 ; T \leq 100^{\circ} \mathrm{C} \\
17.5 ; T=600^{\circ} \mathrm{C} \\
30 ; T \geq 1000^{\circ} \mathrm{C}\end{array}$ & Elastic \\
\hline Bond coat & $\begin{array}{r}140 ; T \leq 100^{\circ} \mathrm{C} \\
70 ; T \geq 1000^{\circ} \mathrm{C}\end{array}$ & 0.3 & $\begin{array}{l}9.35 ; T \leq 100^{\circ} \mathrm{C} \\
16.6 ; T \geq 1000^{\circ} \mathrm{C}\end{array}$ & $\begin{array}{l}27.5 ; T \geq 1000^{\circ} \mathrm{C} \\
12 ; T \leq 100^{\circ} \mathrm{C}\end{array}$ & See Fig. 6 \\
\hline TGO & $\begin{array}{l}357 ; T \leq 100^{\circ} \mathrm{C} \\
319 ; T \geq 1000^{\circ} \mathrm{C}\end{array}$ & 0.2 & $\begin{array}{l}8 ; T \geq 1000^{\circ} \mathrm{C} \\
6.2 ; T \leq 100^{\circ} \mathrm{C}\end{array}$ & $\begin{array}{l}13 ; T \leq 100^{\circ} \mathrm{C} \\
9 ; T=400{ }^{\circ} \mathrm{C} \\
6 ; T \geq 1000^{\circ} \mathrm{C}\end{array}$ & $\begin{array}{l}500 ; T \geq 1000^{\circ} \mathrm{C} \\
\text { Elastic; } T<900^{\circ} \mathrm{C}\end{array}$ \\
\hline
\end{tabular}

The yield strength, coefficient of thermal expansion and thermal conductivity are assumed to vary linearly between the given temperature intervals.

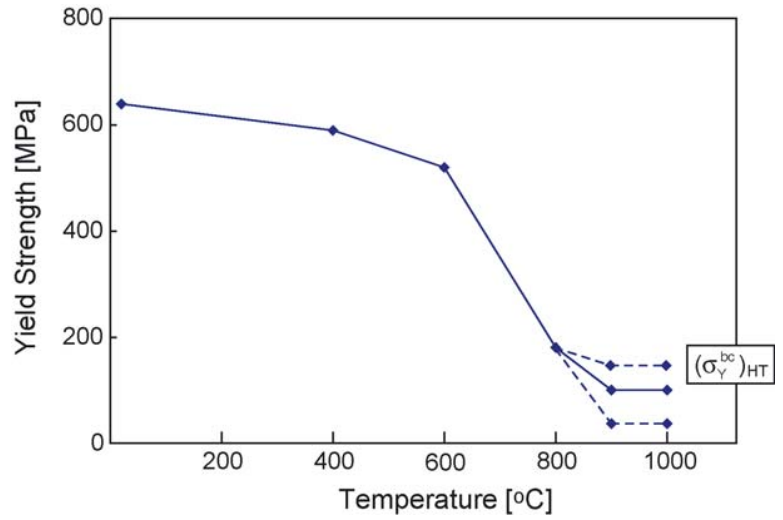

Fig. 6. Yield strength of bond coat as a function of temperature used in the models.

was experimentally seen to prefer the axially oriented grooves, both to circumferential grooves and to random distribution (as observed in TGF).

The material properties are summarized in Table 3 and are based on typical properties for the constituents. For simplicity, we will assume isotropic material response (except where noted). The temperature dependent yield strength is shown in Fig. 6. The (yield or creep) strength at the highest temperatures, $\left(\sigma_{\mathrm{Y}}^{\mathrm{bc}}\right)_{\mathrm{HT}}$, is in general difficult to measure and can be hard to differentiate from each other $[24,25]$. Thus, we will study the effect of the high temperature strength on the morphological instability by varying the value of the high temperature (time independent) yield strength in the calculations. ${ }^{3}$ For morphological instabilities to develop, accumulation of non-elastic strain in the bond coat is important. It does not matter if the non-elastic strain arrives as plastic strain or as creep strain. Creep by itself does not drive morphological instabilities [3]. We will later see that the morphological instabilities are governed by the high tem-

\footnotetext{
3 As noted, the high temperature yield strength can be hard to differentiate from creep properties when conducting material testing. For the current purpose, these properties will be used interchangeably, since we are only interested in accumulation of inelastic strain. Thus, it is immaterial - for the current presentation - if the inelastic strain was obtained from yielding or from creep, even though these are triggered by different physical mechanisms.
}

perature yield properties, whereas the properties below about $700{ }^{\circ} \mathrm{C}$ do not influence the surface instabilities. ${ }^{4}$

At growth (i.e., at max temperature), the TGO is assumed linear-elastic, ideal-plastic, with the yield strength, $\sigma_{\mathrm{Y}}^{\mathrm{tgo}}$. Even though the real mechanism in the TGO is creep, this simplification serves to accumulate inelastic strain during each cycle. $\sigma_{\mathrm{Y}}^{\mathrm{tg}}$ corresponds to what frequently is referred to as "growth stress." Growth in the TGO is imposed as stress-free strain through the user subroutine UEXPAN [23]. Both lengthening and thickening components of the TGO are imposed, where the lengthening component is associated with the growth strain. The accumulation of lengthening growth strain is the key parameter driving the system $[2,3,22]$. For each calculation, we will assume constant growth strain, since we only simulate a fraction of the total number of cycles, thus assuming that the slowdown in oxidation-rate is small within the time frame considered. In the calculations, a thickening growth strain of $5 \times 10^{-3}$ and lengthening of $0.5 \times 10^{-3} \mathrm{cycle}^{-1}$ is applied, unless noted otherwise.

Steady-state heat transfer conditions will be assumed during every time step of the thermo-mechanical cycle. Transient conditions, which result in time dependent (different) temperature differences between the inner and outer surface of the specimen, are simulated by different heating rates at the inner and outer surface of the specimen. This simplification serves to limit the number of parameters in the simulation, yet capture the important parameters governing the morphological instabilities. ${ }^{5}$ The structure is initially stress-free at $1000{ }^{\circ} \mathrm{C}$ (approximately the deposition temperature for the coating). The basic thermal cycle consist of three parts: (1) cooling to low temperature $\left(100^{\circ} \mathrm{C}\right)$, (2) reheating to maximum temperature $\left(1000^{\circ} \mathrm{C}\right)$, and (3) isothermal exposure $\left(1000^{\circ} \mathrm{C}\right)$ where the TGO grows by imposing the stress-free strain. When this temperature sequence is imposed so that the temperature is uniformly distributed over the wall of the cylinder (Fig. 7A), thermal fatigue test is simulated.

\footnotetext{
${ }^{4}$ Due to the uncertainty of the high temperature properties, it follows that the results obtained from the simulations will stipulate in what range the high temperature strength must be for the biased surface instabilities to occur.

5 Including a full heat transfer analyses may show local changes in stresses, but we believe this will not affect the overall behavior of the structure.
} 

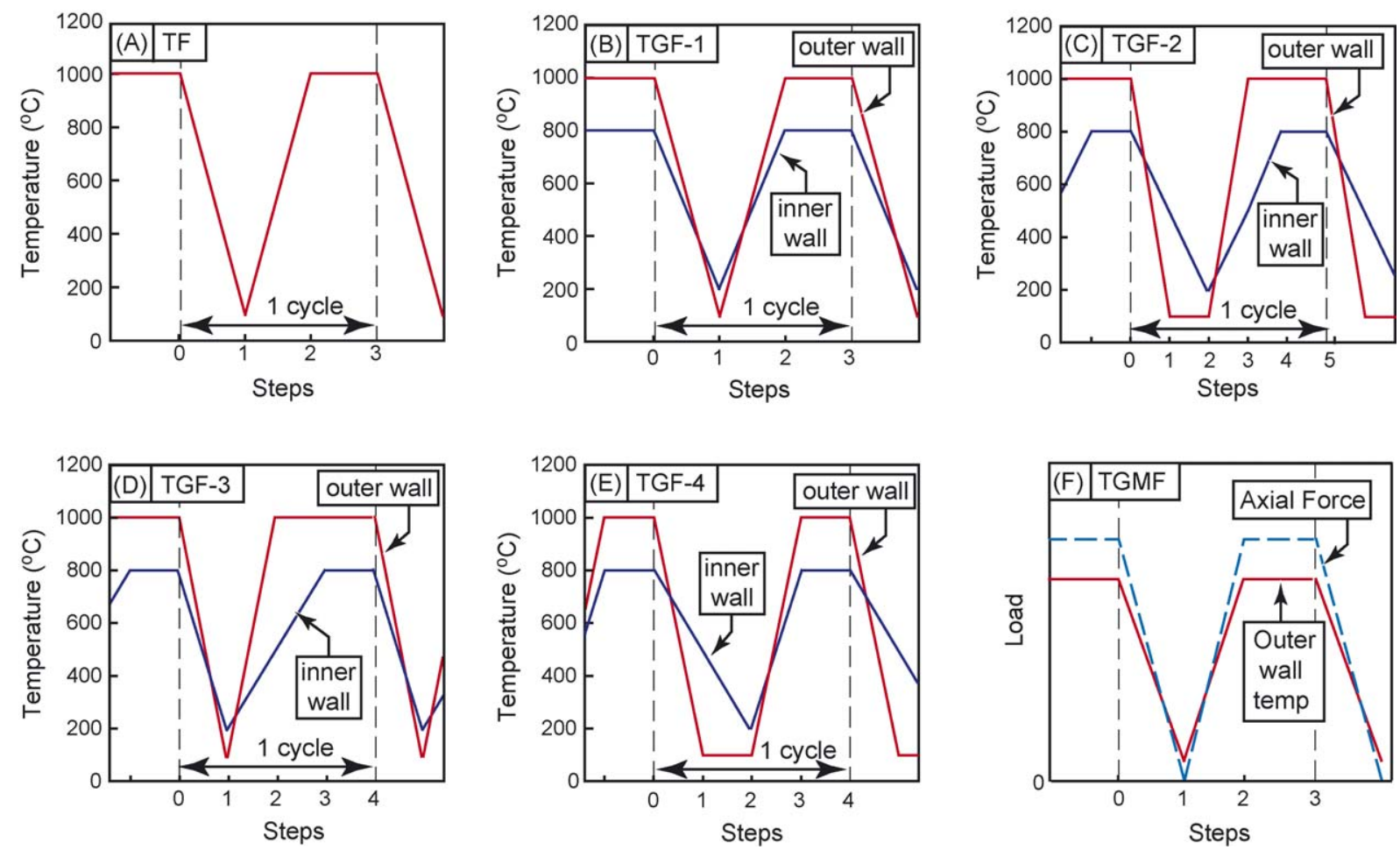

Fig. 7. Schematics of thermal loading sequences used in the simulations where one thermal cycle is marked: (A) thermal fatigue (TF), (B) thermal gradient fatigue with proportional heating-cooling sequence (TGF-1); (C) thermal gradient fatigue with non-proportional heating-cooling: inner wall reach maximum and minimum temperature during heating and cooling, respectively, after the outer wall (TGF-2); (D) thermal gradient fatigue with non-proportional heating, proportional cooling (TGF-3); (E) thermal gradient fatigue with proportional heating, non-proportional cooling (TGF-4); (F) thermal gradient mechanical fatigue TGMF with axial tensile mechanical load, thermal load as TGF-2 (only outer wall temperature shown).

A preliminary study with simplified materials properties indicated that the rate of amplitude growth is influenced by the relative rate of heating and cooling between outer and inner surface of the hollow cylinder [26]. An exact temperature distribution during a load cycle is not available, due to the challenges in measuring the temperatures in situ. In lieu of the true distribution, we will instead study a variety of hypothetical distribution. Here, four heating-cooling sequences simulate the thermal gradient fatigue are investigated:

(i) Thermal gradient fatigue with proportional heatingcooling sequence (TGF-1) (Fig. 7B).

(ii) Thermal gradient fatigue with non-proportional heatingcooling: the inner wall reaches maximum and minimum temperature during heating and cooling after the outer wall, TGF-2 (Fig. 7C).

(iii) Thermal gradient fatigue with non-proportional heating, proportional cooling, TGF-3 (Fig. 7D).

(iv) Thermal Gradient Fatigue with proportional heating, nonproportional cooling, TGF-4 (Fig. 7E).

We believe that the case TGF-2 (thermal gradient fatigue of the second kind), corresponds most closely to the thermal cycling in the actual testing [10], assuming that the heating of the inner surface reaches its highest temperature after the outside, based on the discussion in Section 2. TGF-1 and TGF3 were investigated in a previous study [26], TGF-4 is added for completeness as a hypothetical heating-cooling sequence.
Altogether, these cases will elucidate the effect of the thermal gradient and the relative heating/cooling rate.

Thermal gradient mechanical fatigue (Fig. 2C) is simulated by using TGF-2 and superimposing the axial tensile load, which is synchronized with the thermal cyclic, as illustrated in Fig. 7F.

\subsection{Results from numerical simulations}

\subsubsection{Thermal loading only}

Consider first the cases without axial force (TF and TGF, Table 1 and Fig. $7 \mathrm{~A}-\mathrm{E})$, assuming that $\left(\sigma_{\mathrm{Y}}^{\mathrm{bc}}\right)_{\mathrm{HT}}=50 \mathrm{MPa}$. The evolution of morphological instabilities will be monitored through the amplitude change, $\Delta A$, of the initial imperfection, $A_{0}$. The numerical simulations, simulating the 24 first cycles, reveal that the development of morphological instabilities depends on both the thermal gradient and the timing of the heating and cooling, manifested as a cyclic increase of the total amplitude (Fig. 8A). The case without thermal gradient, TF, along with two approximations of the thermal gradient fatigue, TGF-1 and TGF-4, exhibit a low rate of amplitude growth (the results from TF and TGF-1 coincide with each other within the resolution of the figure), whereas the other two thermal gradient fatigue approximations (TGF-2 and TGF-3) show significantly higher amplitude growth rate (Fig. 8A). Thus, the results presented in Fig. 8A suggest that (i) a thermal gradient has to be present at the maximum temperature and (ii) the heating sequence must have a disproportional loading sequence (which imposes a large thermal gradient over the cylinder wall 


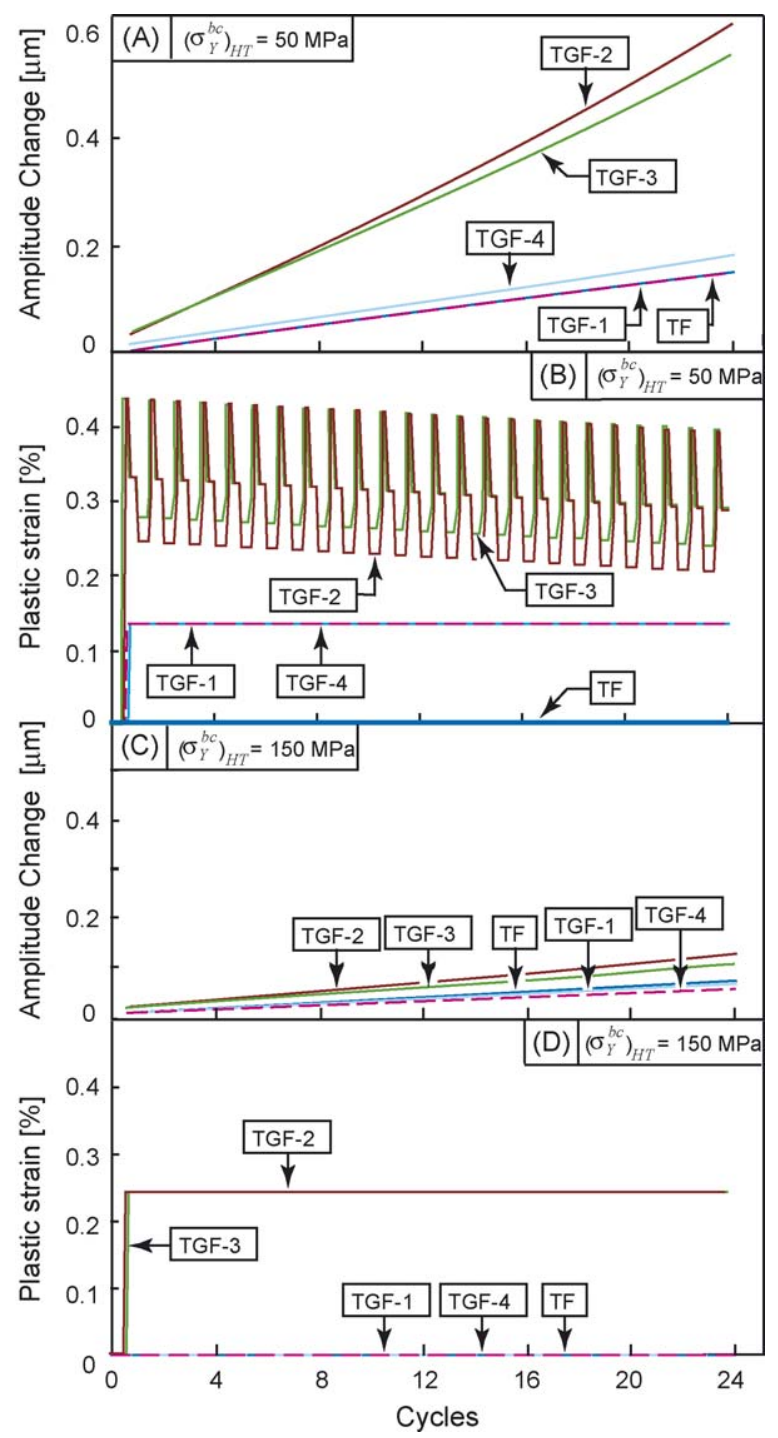

Fig. 8. For $\left(\sigma_{\mathrm{Y}}^{\mathrm{bc}}\right)_{\mathrm{HT}}=50 \mathrm{MPa}(\mathrm{A})$ total amplitude change and (B) accumulation of plastic strain; and for $\left(\sigma_{\mathrm{Y}}^{\mathrm{bc}}\right)_{\mathrm{HT}}=150 \mathrm{MPa}(\mathrm{C})$ total amplitude change and (D) accumulation of plastic strain, as a function of thermal cycles. The accumulation of plastic strains is considered in regions "far away" from the imperfection, and corresponds to the overall behavior of the bond coat (simulating a circumferential groove.).

during heating and/or cooling) for morphological instabilities to develop for this class of structures. These two observations will be explained in the following, starting with the latter observation.

The sensitivity for the heating-cooling rate is due to the temperature distribution over the cylinder wall during heating and cooling, and the overall plastic yielding in the bond coat (yielding far away from the imperfection) during cycling. Depending on the relative heating-cooling rate between the inner and outer wall, a temperature difference may be introduced that is temporarily larger than the $200^{\circ} \mathrm{C}$ difference over the wall thickness at maximum temperature. For the case of TGF-2, a temporarily temperature difference of $500^{\circ} \mathrm{C}$ is obtained during heating (Fig. 9D). A similar temperature difference is observed for TGF3 , shown in our preliminary work [26]. As seen from Fig. 3 and discussed in Section 3, the gradient will introduce a large bond coat stress, resulting in overall yielding of the bond coat (Fig. 9A). It was shown by Shi et al. [20], and discussed in Section 3 , that overall yielding in the bond coat (far away from the imperfection) during the thermal cycling has a significant influence over the imperfection growth. Here, we see that the majority of the amplitude change is accumulated during the maximum temperature difference during heating for TGF-2 (Fig. 9C).

In the current case, overall bond coat yielding occurs on a cyclic basis for the TGF-2 and TGF-3 approximations, manifested as a cyclic accumulation of cyclic strain as show in Fig. 8B. Contrary, overall yielding occurs only during the first cycle for TGF-1 and TGF-4, with the bond coat remaining elastic during further cycling (Fig. 8B) (except adjacent to the TGO, not shown). Thus, TGF-2 and TGF-3 accumulate significant amplitude change, and the other cases do not (Fig. 8A). When a higher bond coat yield strength is used (e.g., $\left.\left(\sigma_{\mathrm{Y}}^{\mathrm{bc}}\right)_{\mathrm{HT}}=150 \mathrm{MPa}\right)$, the overall yielding of bond coat in all loading types is suppressed, and the amplitude change for all cases is very small (Fig. 8C and D). The observation of the suppressing character of increased high temperature yield strength is consistent with previous work on morphological instability for systems without thermal gradient and/or axial force [2,27,28].

For the case of TGF-4, there will be a large thermal gradient during cooling. However, that occurs when the bond coat has reached relatively low temperatures, within the range of large yield strengths, suppressing yielding. Thus, in this case, the bond coat does not yield in a cyclic manner, limiting the amplitude change significantly.

Thus, the non-proportional heating introduces a larger thermal gradient, causing overall larger stresses compared to proportional heating. For the set of properties investigated, these stresses surpass the bond coat yield strength, resulting in overall bond coat yielding, which in turns encourage amplitude growth at an imperfection. Once the bond coat experiences overall yielding, the TGO can relax its compressive stresses by distorting the bond coat-TGO interface and increasing its undulation amplitude. From this argument, it follows directly that the case of TF, with uniform temperature distribution, will not exhibit any significant amplitude change.

We note that all accumulation of non-elastic strain occurs at high temperatures, approximately above $700{ }^{\circ} \mathrm{C}$ (not shown for brevity). Thus, the results suggest that properties at lower temperatures do not (significantly) affect the evolution of the morphology. (The properties at lower temperatures will of course influence the stresses at these temperatures and could for example be critical for crack evolution-a discussion left for a future study.)

The model simulating the axial grooves gives similar results as when simulating the circumferential grooves (Figs. 10 and 11). Comparing Fig. 10 to Fig. 9, it is evident that the cyclic behavior follows the same trends. From Fig. 11, it is seen that the models predict similar amplitude change (after 24 cycles) for a large range of possible high temperature bond coat strengths, thus suggesting that the amplitude growth will not have any preference between a circumferential or axial groove. This suggests that the undulation growth will appear at random, as was seen in the experiments. 


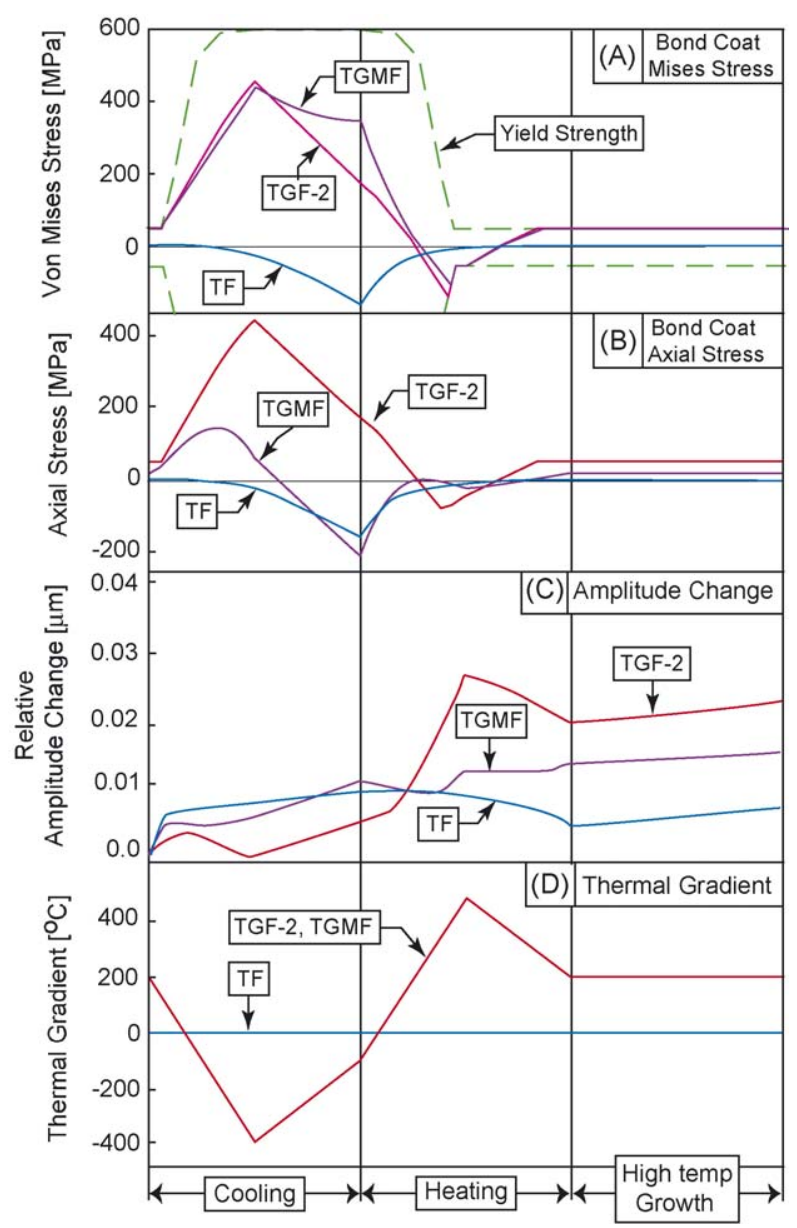

Fig. 9. For a typical thermal cycle (TF, TGF-2, and TGMF) when simulating a circumferential groove: (A) mises stress in the bond coat and the bond coat yield strength; (B) axial stress in the bond coat (corresponding to the "in-plane" stress over the imperfection), (C) amplitude change and (D) temperature difference over the wall thickness. The majority of the amplitude change is accumulated during the maximum temperature difference during heating for TGF-2. The bond coat stresses are considered in regions "far away" from the imperfection and correspond to the overall bond coat behavior.

The main difference between the two models arise when the axial force is applied, which will be discussed next.

\subsubsection{Effect of axial tensile force}

The case of TGMF, including both a thermal gradient and an axial tensile force (Fig. 7F), will now be discussed. As mentioned previously, the model simulating an axial groove is expected to result in higher amplitude change than the model simulating circumferential a groove, since the imperfection was experimentally seen to prefer the axial grooves to both circumferential grooves and to random distribution. The axial tensile force is imposed by a constant strain of $0.07 \%$ (causing an added tensile stress of about $200 \mathrm{MPa}$, Fig. 12A).

Comparing the results for the two models after 24 cycles (Fig. 11), it is evident that TGMF imposes significantly higher amplitude change than TGF when simulating an axial groove for $\left(\sigma_{\mathrm{Y}}^{\mathrm{bc}}\right)_{\mathrm{HT}}<100 \mathrm{MPa}$, predicting about 50\% higher amplitude change for TGMF than for TGF. When considering the model simulating a circumferential groove, TGMF results in somewhat

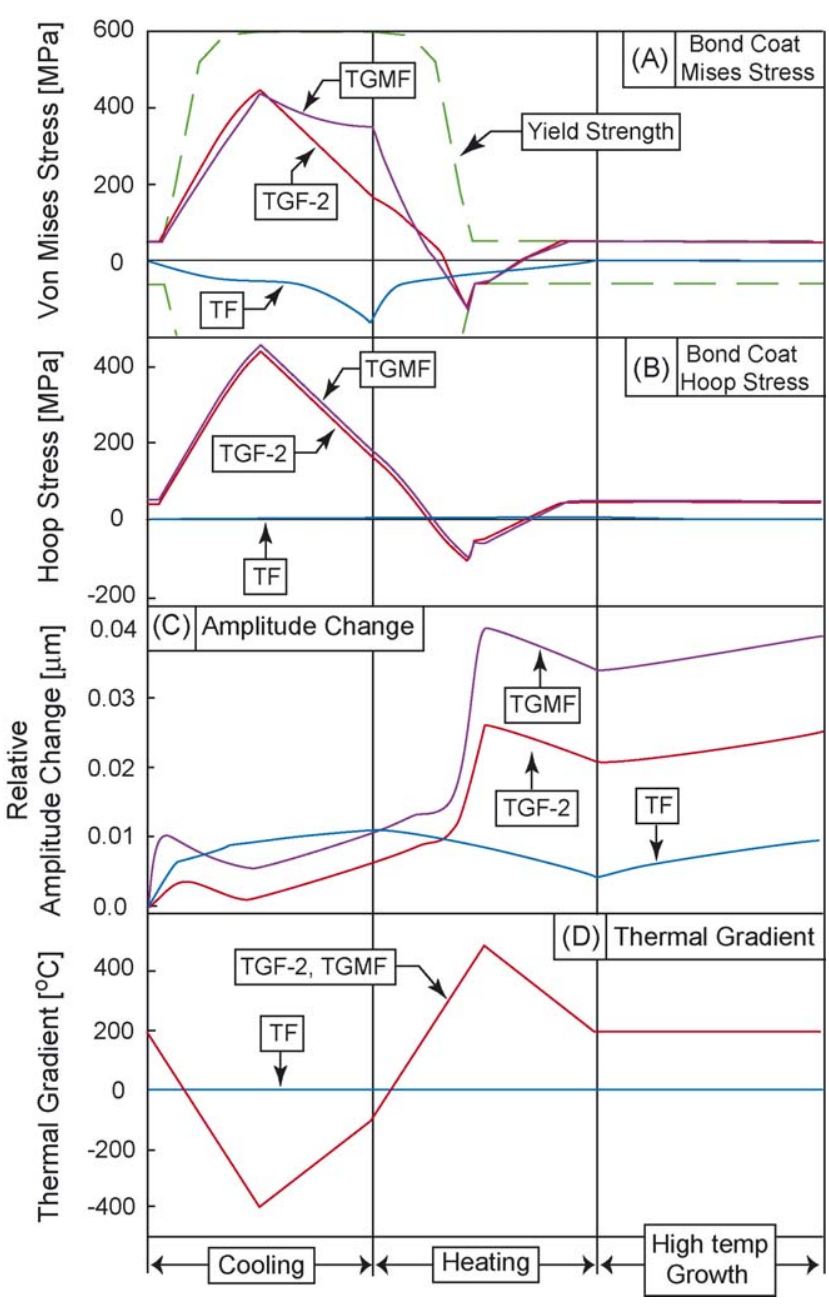

Fig. 10. For a typical thermal cycle (TF, TGF-2, and TGMF) when simulating an axial groove (A) mises stress in the bond coat and the bond coat yield strength; (B) hoop stress in the bond coat (corresponding to the "in-plane" stress over the imperfection), (C) amplitude change, (D) temperature difference over the wall thickness. The majority of the amplitude change is accumulated during the maximum temperature difference during heating for TGF-2 and TGMF. The bond coat stresses are considered in regions "far away" from the imperfection and correspond to the overall bond coat behavior.

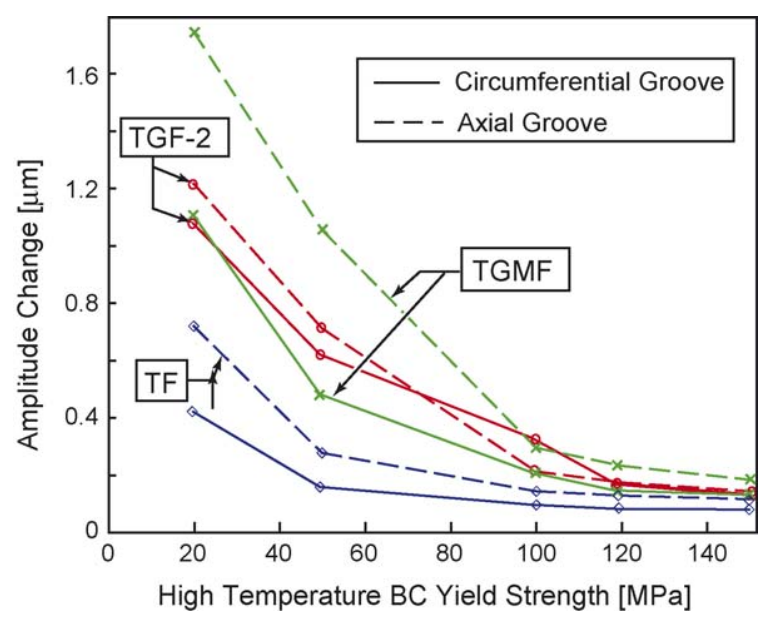

Fig. 11. The amplitude change after 24 thermal cycles as a function of high temperature bond coat yield strength. 


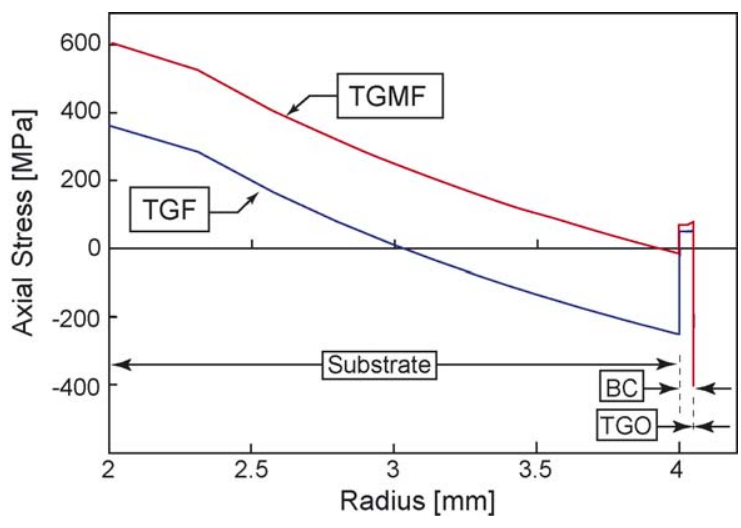

Fig. 12. The axial stress as a function of radius of the cylinder specimen at maximum temperature.

lower values than TGF. Together, this suggests that the axial grooves must be the preferred configuration.

In general, the response is governed by that the axial tensile force redistributes the stresses around the assumed grooves, and enhance the compressive stresses in the axial grooves, augmenting their growth, while suppressing circumferential grooves. A detailed analysis and explanation to this is given by the following paragraphs.

A compressive stress that is "in-plane" with the undulation increases the amplitude change [20], illustrated in Fig. 4 and discussed in Section 3. When simulating the circumferential groove, the axial stress in the bond coat corresponds to the "inplane" stress with the undulation, whereas when simulating the axial groove, the "in-plane" stress corresponds to the circumferential (hoop) stress. The development of these stress components over one thermal cycle (for the cases TF, TGF-2, and TGMF) is shown in Figs. 9B and 10B for the two models, respectively. It may be seen that, when a circumferential groove is assumed, the "in-plane" stress (axial stress, Fig. 9B) for the case of TGMF, is significantly smaller than for TGF-2 and almost vanishes during heating. When simulating the axial groove, the "in-plane" stress is almost unchanged between TGF and TGMF (Fig. 10B). Moreover, comparing the "in-plane stress" for the two models, it may be seen that this component is much smaller when

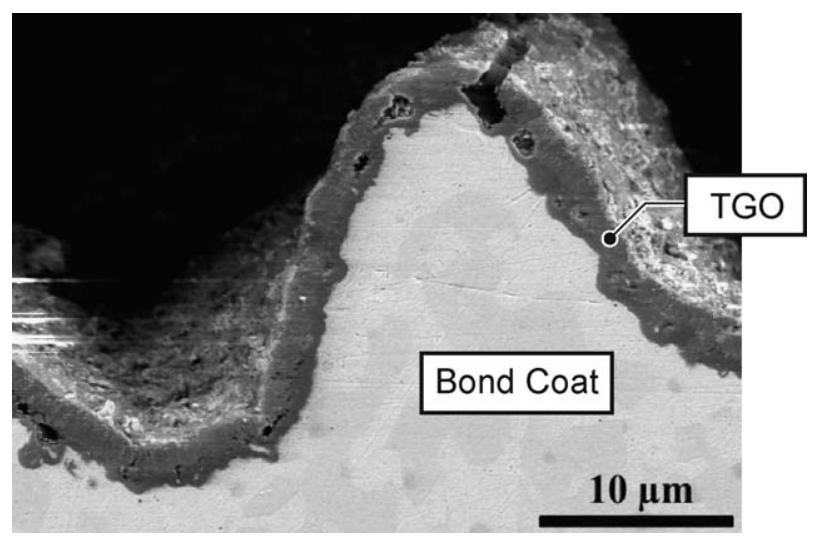

Fig. 13. SEM-image of a cross-section showing large amplitude change after 18 TGMF cycles due to increased maximum temperature to $1080^{\circ} \mathrm{C}$. simulating the circumferential grooves than the axial groove (Figs. 9B and 10B).

Next, when consider the incremental amplitude change (Figs. 9C and 10C) it may be seen that a significant part of the amplitude change occurs during heating for both models simulating TGF-2, whereas only the model simulating axial grooves predicts significant amplitude change for TGMF. Lastly, comparing the incremental amplitude change to the "in-plane stress" (axial when simulating a circumferential groove, Fig. 9B, and hoop when simulating an axial groove, Fig. 10B), it can be seen that the amplitude growth is associated with the compressive "in-plane stress," when the bond coat stress exceeds the yield strength. This is what differentiates the response between the two models and together with the overall results presented in
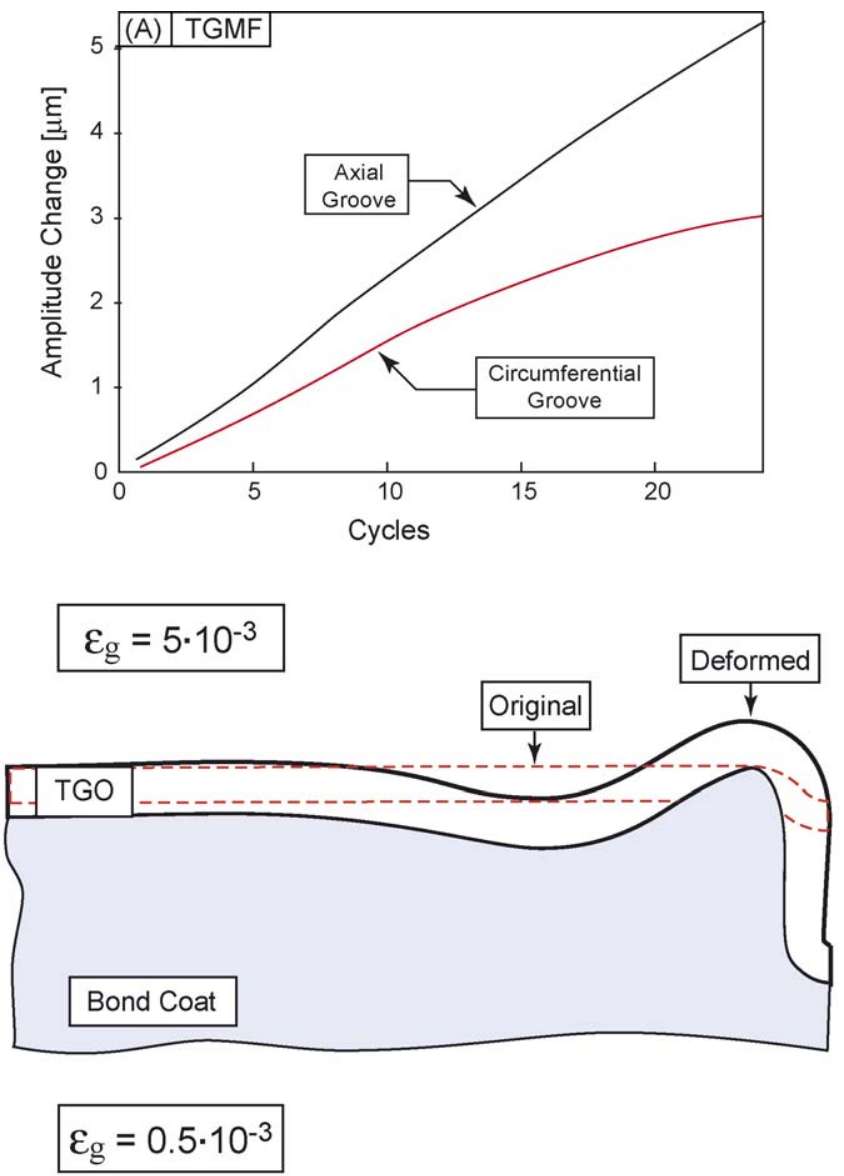

(B)

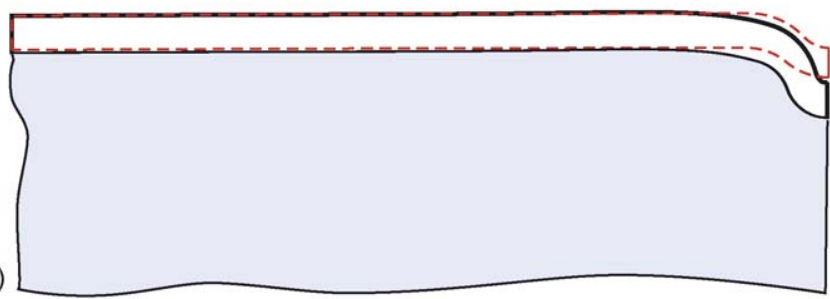

Fig. 14. Numerical simulation capturing results for higher amplitude change at $T_{\max }=1080^{\circ} \mathrm{C}, \varepsilon_{\mathrm{g}}=5 \times 10^{-3}$ and $\left(\sigma_{\mathrm{Y}}^{\mathrm{bc}}\right)_{\mathrm{HT}}=50 \mathrm{MPa}$. (A) Evolution of the two models as a function of time, per cycle and (B) shape of the TGO (assuming axial grooves) before and after thermal cycling for high $\left(\varepsilon_{\mathrm{g}}=5 \times 10^{-3}\right)$ and low $\left(\varepsilon_{\mathrm{g}}=0.5 \times 10^{-3}\right)$ growth strain rate (the latter used for all other simulations). 
Fig. 11 confirms that undulation growth will be preferred to appear as grooves aligned with the axial direction.

\subsubsection{Evolution for higher maximum temperatures}

Samples subjected to higher maximum temperatures $\left(1080^{\circ} \mathrm{C}\right.$ instead of $\left.1000^{\circ} \mathrm{C}\right)$, exhibit significantly larger amplitude change, resulting in undulations of up to $20 \mu \mathrm{m}$ after only 18 TGMF-cycles (Fig. 13). These undulations are aligned in a similar manner as was seen for the previously discussed experimental investigations.

At this higher temperature, the bond coat strength may be significantly lower, and the growth strain significantly higher. Fig. 11 indicates that lower high temperature yield strength results in increasing amplitude growth and it has previously been seen that changes in the growth strain rate alters the rate of amplitude growth. To verify that this holds for the current model, we conduct simulations assuming a higher lengthening growth strain $\varepsilon_{g}=5 \times 10^{-3}$ cycle $^{-1}$ (compared to $\varepsilon_{g}=0.5 \times 10^{-3}$ for previous simulations) (Fig. 14). The amplitude growth when simulating the axial groove is significantly higher than when simulating the circumferential groove (Fig. 14A). Thus, the amplitude growth is biased so that axially oriented grooves occur, consistent with previous results. Fig. 14A also shows significantly higher amplitude change when comparing to the lower growth strain rate, as summarized in Fig. 11. Finally, we note that the final shape (Fig. 14B) show similar deformation pattern as for the experimental observations (Fig. 13). However, the numerical simulations only capture the results qualitatively, not quantitatively. We believe that the numerical values are not accurate primarily due to the lack of reliable values of high temperature properties for the TGO and the bond coat. Moreover, the simplified models, i.e., not a full 3D-model and assuming isotropic material properties, may not result in quantitatively correct results.

\section{Concluding remarks}

The evolution of surface morphologies for a NiCoCrAlY bond coat observed after thermal mechanical gradient fatigue testing is investigated. The morphological surface instabilities were observed when hollow, circular cylinders of the superalloycoating systems were thermo-mechanically cycled, with the bond coat exposed due to pre-spalling of the ceramic top coat.

To capture the behavior, mechanics based numerical models that predict such behaviors have been developed. The numerical models utilize finite element simulations and consist of two carefully designed two-dimensional models that together capture the three-dimensional behavior. The results presented herein verify that the system is very sensitive for the relative heating rate of the inner and outer side of the circular, hollow cylinder. Furthermore, the models predict that materials with lower yield and creep strengths at high temperature are more prone to morphological instabilities.

Key features are: (1) the thermal gradient over the cylinder wall during the high temperature exposure imposes an elevated stress level in the bond coat; (2) the non-proportional heating-cooling sequence of the inner and outer side of the cylinder may induce temporary large thermal gradients, causing enhanced stresses in the bond coat; (3) the overall yielding in the bond coat, induced due to the thermal gradient, enables the morphological instabilities to develop; (4) the presence of an axial tensile force alters the stress state in the bond coat so that the morphological instabilities align with the axial direction.

The experimental and numerical results suggest that a $\mathrm{NiC}$ oCrAlY bond coat can develop morphological instabilities if the mismatch strain imposed on the bond coat become "large enough," i.e., large enough to induce overall yielding in the bond coat. In this case, the mismatch strain is due to a thermal gradient that can become large, depending on how the heating/cooling sequence is conducted. This may explain why surface instabilities have been observed on MCrAlY alloys in service conditions but not (to the knowledge of the authors) in "conventional" cyclic furnace tests for the relatively low temperature range used here. In service conditions, the turbine blades are cooled internally, imposing a temperature gradient over the structure, similar to our experimental setup. Thus, we believe that the experimental setup used in the current investigation may be a critical tool for simulating the conditions of a coating in service.

\section{Acknowledgments}

The authors like to acknowledge the financial support by NSF DMR-0346664 and thank Klaus Mull and Christian Sick from the German Aerospace Center for their experimental support.

\section{Appendix A}

The evolution of the TGO morphology (roughening of the bond coat surface) that occurs due to cyclic thermo-mechanical loading, but not during isothermal conditions, is referred to as morphological instabilities (or sometimes ratcheting). Surface roughening that occurs during isothermal conditions does not belong to this class of problems. This phenomena has received significant attention over the last few years, see for example [2,3,6,16,20,22,27-29], and will be summarized here.

The morphological instabilities evolve due to the compressive stresses that build in the TGO during thermal exposure combined with thermal cycling. The compressive stresses are caused by a combination of the thermal expansion mismatch between the TGO and the bond coat during the cooling/heating sequence and by the growth strain developing in the TGO during formation of the alumina. The compressive stresses can reach several GPa at ambient conditions $[2,30,31]$. The TGO strive to relax the compressive stress by deforming out of its plane, deforming the bond coat. The mechanism is driven by a combination of three non-linear constitutive behaviors in the layered coating: (1) high temperature inelasticity in the TGO; (2) growth strain in the TGO; (3) cyclic inelasticity in the bond coat. The growth strain is driving the system $[2,3,27]$. If the lengthening component of the aluminum formation is removed, the morphological instabilities cannot occur [2,22].

The growth strain is induced due to the oxidation process when the new alumina is formed [1,30,32,33]. Most of the TGO growth occurs as thickening, but a small part is distributed in the 


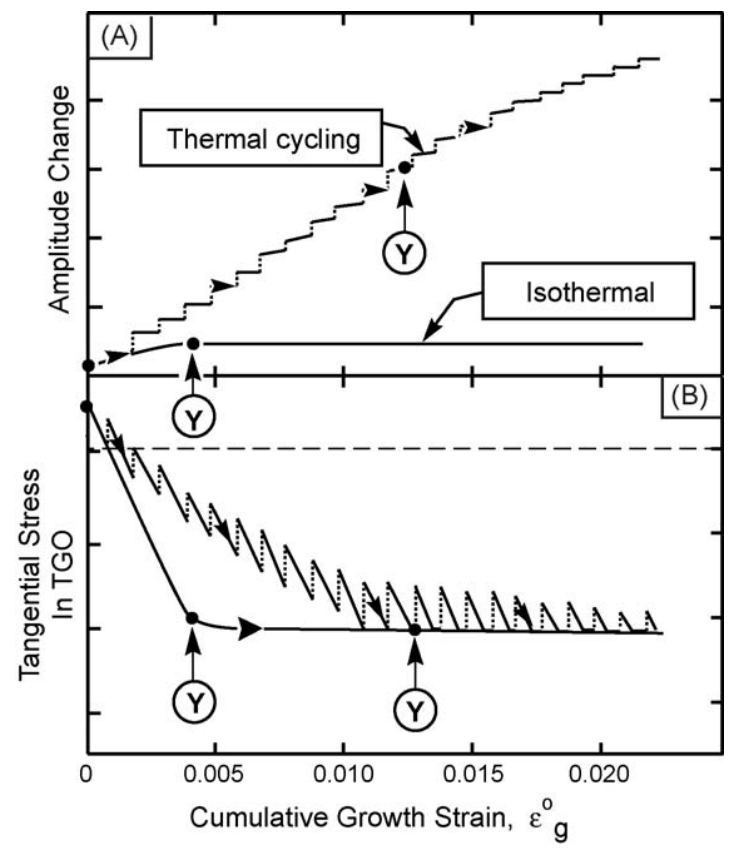

Fig. A.1. Cyclic and isothermal scenarios are compared schematically, as a function of the cumulative growth strain in the TGO, showing (A) amplitude increase, (B) tangential stress in the TGO. The positions designated $\mathrm{Y}$ refer to the onset of TGO inelasticity, e.g., the growth stress is reached. In the isothermal scenario, the changes in the displacement essentially stop. However, under cyclic conditions, displacements and stresses continue to change even after the TGO inelasticity is reached.

grains of the TGO leading to a lengthening component. The high temperature inelastic strength of the TGO is often referred to as the "growth stress." The growth strain is limited by the growth stress, and once the TGO stress reaches the level of the growth stress, the lengthening strain is reallocated into thickening strain. In Fig. A.1, the cases of cyclic versus isothermal scenario are compared, as a function of cumulative growth strain, showing (a) amplitude increase, and (b) tangential stress in the TGO (i.e., stresses parallel to the interface of the bond coat and TGO). The position designated Y refers to the onset of TGO inelasticity, e.g., the growth stress is reached. In the isothermal scenario, the amplitude change essentially stops, whereas under cyclic conditions, displacements and stresses continue to change after the point of TGO inelasticity is reached. This is so, since the stress in the TGO is relaxed during each cycle, allowing for additional accumulation of lengthening strain in the TGO at high temperatures. Morphological instabilities are governed by the state of stress in the bond coat in combination with the inelastic strain of the bond coat at high temperatures, since the inelasticity (plasticity or creep) in the bond coat allows the TGO to relax and deform out of plane - into the bond coat - for each thermal cycle. The primary function of the growth stress is to differentiate between isothermal and thermal cyclic exposure: if the growth stress is assumed to be infinite (i.e., the TGO is fully elastic) isothermal conditions will result in large amplitude changes as well [3].

Some factors can suppress morphological instabilities, for example, a full adherence of the ceramic top coat to the
TGO/bond coat [28] or high yield strength of the bond coat [3]. The suppressive effect of high yield strength in the bond coat can be compromised if other factors are combined in the thermo-mechanical loading cycle, such as increased bond coat stresses due to a thermal mismatch with the bond coat [20] or thermo-mechanical loading, explored in this study.

There are a group of factors that can enhance the rate of instability growth, including bond coat swelling [34], martensitic phase transformation [20,22], or permanent phase transformations of grains [29]. It is important to note that in all these cases, the rate of amplitude growth changes, but if the lengthening growth strain is not present, morphological instabilities do not occur.

\section{References}

[1] A.G. Evans, D.R. Mumm, J.W. Hutchinson, G.H. Meier, F.S. Petit, Prog. Mater. Sci. 46 (2001) 505-553.

[2] A.M. Karlsson, A.G. Evans, Acta Mater. 49 (10) (2001) 1793-1804.

[3] A.M. Karlsson, J.W. Hutchinson, A.G. Evans, Mater. Sci. Eng. A-Struct. Mater. Prop. Microstruct. Process. 351 (1-2) (2003) 244-257.

[4] D.R. Mumm, A.G. Evans, I.T. Spitsberg, Acta Mater. 49 (2001) 2329 2340.

[5] I.T. Spitsberg, D.R. Mumm, A.G. Evans, Mater. Sci. Eng. A-Struct. Mater. Prop. Microstruct. Process. 394 (1-2) (2005) 176-191.

[6] M.Y. He, A.G. Evans, J.W. Hutchinson, Acta Mater. 48 (10) (2000) 2593-2601.

[7] S. Sridharan, L. Xie, E. Jordan, M. Gell, Surf. Coat. Technol. 179 (2-3) (2004) 286-296.

[8] R. Pennefather, D. Boone, Surf. Coat. Technol. 76 (1-3) (1995) 47-52.

[9] R. Pennefather, D. Boone, Int. J. Pressure Vessels Piping 66 (1-3) (1996) 351-358.

[10] M. Bartsch, B. Baufeld, E.R. Fuller, Ceram. Eng. Sci. Proc. 24 (3) (2003) 497-502.

[11] M. Bartsch, B. Baufeld, Proceedings of the Fifth International Conference on Low Cycle Fatigue, 2003, pp. 183-188.

[12] M. Bartsch, K. Mull, C. Sick, ASTM STP 1417 (2002) 147-160.

[13] R.A. Miller, J. Am. Ceram. Soc. 67 (8) (1984) 517-521.

[14] T.E. Strangman, Thin Solid Films 127 (1-2) (1985) 93-105.

[15] M. Bartsch, G. Marci, K. Mull, C. Sick, Adv. Eng. Mater. 2 (11) (1999) $127-129$.

[16] A.M. Karlsson, T. Xu, A.G. Evans, Acta Mater. 50 (5) (2002) 12111218.

[17] M.D. Burghardt, Engineering Thermodynamics with Applications, third ed., Harper \& Row, New York, NY, 1986.

[18] B.A. Boley, J.H. Weiner, Theory of Thermal Stresses, Dover Publications, Mineola, NY, 1988

[19] D. Wagus, A.M. Karlsson, A closed for solution for a multilayered hollow cylinder subjected to a thermal gradient, in preparation.

[20] J. Shi, S. Darzens, A.M. Karlsson, Mater. Sci. Eng. A-Struct. Mater. Prop. Microstruct. Process. 392 (1-2) (2005) 301-312.

[21] S. Darzens, A. Karlsson, Surf. Coat. Technol. 177-178C (2004) 108112

[22] A.M. Karlsson, J. Eng. Mater. Technol.-Trans. Asme 125 (4) (2003) 346-352.

[23] ABAQUS, ABAQUS 6.3 User's Manual, ABAQUS Inc., Pawtucket, Rhode Island, 2003

[24] M.W. Chen, R. Ott, T.C. Hufnagel, P.K. Wright, K.J. Hemker, Surf. Coat. Technol. 163 (2003) 25-30.

[25] D. Pan, M.W. Chen, P.K. Wright, K.J. Hemker, Acta Mater. 51 (8) (2003) 2205-2217.

[26] J. Shi, A.M. Karlsson, B. Baufeld, M. Bartsch, 29th International Conference on Advanced Ceramics and Composites 26 (3), 2005, pp. 65-72.

[27] A.M. Karlsson, J.W. Hutchinson, A.G. Evans, J. Mech. Phys. Solids 50 (8) (2002) 1565-1589. 
[28] A.M. Karlsson, C.G. Levi, A.G. Evans, Acta Mater. 50 (6) (2002) 1263-1273.

[29] S. Darzens, A.M. Karlsson, Surf. Coat. Technol. 177-178C (2004) 108-112.

[30] V.K. Tolpygo, J.R. Dryden, D.R. Clarke, Acta Mater. 46 (3) (1998) 927-937.
[31] T. Tomimatsu, S.J. Zhu, Y. Kagawa, Scripta Mater. 50 (1) (2004) 137141.

[32] D.R. Clarke, Curr. Opin. Solid State Mater. Sci. 6 (3) (2002) $237-$ 244.

[33] D.R. Clarke, Acta Mater. 51 (5) (2003) 1393-1407.

[34] A.W. Davis, A.G. Evans, Acta Mater. 53 (7) (2005) 1895-1905. 